\title{
OS SEFARDITAS DE BELÉM DO PARÁ: HISTÓRIA E LÍNGUA
}

\author{
Cássia Scheinbein*
}

Resumo: A contextualização sócio-histórica do hakitia, língua românica e judaica, em avançado processo de extinção, na comunidade sefardita de Belém do Pará, Brasil, é apresentada neste artigo. Descreve-se sua formação a partir do século XV, como consequência da diáspora dos judeus da Hispânia Medieval, até os dias atuais no Brasil. Especial relevância é dada à sua inserção cultural ao longo desse período de tempo. Uma lista de provérbios e frases, com base em dados linguísticos atuais coletados na cidade, está presente no final deste artigo.

Palavras-chave: Contato linguístico; judeu-espanhol; sefardita; hakitia; provérbios.

\section{Antecedentes históricos: a Hispânia Medieval e o Marrocos}

Neste artigo trataremos da comunidade sefardita de Belém do Pará e dos resquícios de sua língua: o hakitia, língua neolatina e judaica, em avançado processo de extinção. Começaremos por contextualizar sócio-historicamente a comunidade, pois, para se

* Mestre em Linguística pela Faculdade de Letras da UFMG. 
descrever a língua de um povo em uma determinada região, fazse necessária a sua inserção num contexto cultural, já que as línguas acompanham o homem em suas vicissitudes.

A comunidade que é o objeto deste trabalho, a dos judeus sefarditas de Belém do Pará, na região norte do Brasil, tem como origem os judeus que não aceitaram converter-se ao catolicismo e que, sob ameaça de morte e de confisco de bens, foram expulsos da Espanha em 31 de Março de 1492, pelo rei Fernando e pela rainha Isabel.

Estima-se que, nessa época, entre 100.000 e 175.000 judeus foram forçosamente exilados. Estes, que passaram a ser conhecidos por sefarditas, ou sefaradins, a partir do topônimo Sefarad, nome hebraico utilizado para designar a Espanha e a Península Ibérica na Idade Média, seguiram três rotas principais de exílio:

a) a maioria imigrou para o Império Otomano. A sua história e o desenvolvimento de sua língua é muito diferente da dos sefarditas ocidentais.

b) muitos dos expulsos da Espanha refugiaram-se em Portugal, tendo sido mais tarde ou submetidos a um batismo forçado ou de lá expulsos em 1497. Com outros judeus portugueses, esse grupo foi principalmente para a Holanda, França, Inglaterra, Alemanha, e outros países europeus ocidentais. Esses sefarditas ocidentais mantinham contato com a Espanha e Portugal e ficaram expostos às línguas, à literatura e outras influências da Península Ibérica. Assim, continuaram a falar uma modalidade da língua portuguesa e espanhola semelhantes às que se desenvolviam em Portugal e Espanha, mas foram levados também a adotar as línguas dos países onde se instalaram, tais como o holandês, o francês, o inglês e o alemão, já à época línguas de cultura.

c) Norte da África, especialmente o norte do Marrocos, onde construíram consideráveis comunidades em cidades como Tânger, Oran, Fez, Tetuan e Meknes. A língua que se formou aí, o hakitia, mesclou o espanhol com o hebraico e o árabe. 
Bemerguy $^{1}$ menciona que o Marrocos já havia sido refúgio para os judeus em decorrência das perseguições religiosas dos reis visigodos nos séculos VI e VII, mas é nos séculos XV e XVI que tem lugar o maior contingente migratório para esse país, em função dos problemas gerados pela Inquisição na Península Ibérica.

Os judeus vindos da Ibéria ficaram confinados em guetos denominados melachs, em Tetuan, Fez, Marrakesh e outras vilas e cidades. A escolha do Marrocos explica-se dada a sua proximidade com a Península Ibérica. Os expulsos aí ficaram por 300 anos, falando espanhol, português e hakitia. Reconstruíram as suas comunidades em Tetuan, Tânger, Fez, Rabat, Salé, Marrakesh, Arcila, Larache, Ceuta e Melila. Saíram da guezerá (sentença maldita) da Ibéria para o guechinam (inferno) do Marrocos.

A situação econômica não era a mesma para todos os judeus marroquinos, variava conforme a região, mas a maioria da população sofria privações.

Os megorashim ("expulsos") chamavam a seus irmãos judeus nativos de forasteiros, ou seja, estrangeiros em relação à comunidade judia de origem espanhola. Não foram bem recebidos pelos judeus nativos, os tochabim, porque os recém-chegados, tendo assumido a liderança nas juderias e melachs, progrediram em seus negócios e profissões, ao contrário dos nativos empobrecidos por séculos de dominação moura e berbere, sem oportunidade de educação e profissionalização. Esses temiam os judeus vindos da Espanha. A rivalidade e divergências entre os dois grupos de judeus manifestou-se no campo social, comercial e religioso. Os judeus espanhóis e portugueses de Tânger e Tetuan se achavam superiores pela sua posição social, por seu status econômico e profissional. Essa rivalidade e divergências foram levadas para a nova diáspora, o norte do Brasil, no início do século XIX.

\footnotetext{
${ }^{1}$ BEMERGUY. Imagens da ilusão: judeus marroquinos em busca de uma terra sem males - Pará, 1870-1910.
} 
Fatores políticos, econômicos, sociais, religiosos e educacionais foram os motivos que desencadearam a onda migratória dos judeus sefarditas e dos chamados forasteiros marroquinos para a Amazônia.

A vida dos judeus no Marrocos atingiu um grande nível de pobreza nos melachs, em cidades como Tetuan, Tânger, Fez, Marrakesh, Salé, Arcila e outras. Poucas famílias judias sefarditas de Tetuan e Tânger (portos do Mediterrâneo e do Atlântico), em frente a Gibraltar, desfrutaram de melhor posição social e econômica. A maioria vivia confinada nos melachs e insalubres juderias, sujeitos a doenças e epidemias. Laredo ${ }^{2}$ menciona que 0 estado de pobreza dos judeus era tão grande que existiam 22 sociedades judias de beneficiência e de socorro. As condições sanitárias das cidades marroquinas eram péssimas e piores nos melachs. Diversas epidemias ocorreram em várias ocasiões, entre elas, de cólera. A fome agravava as enfermidades.

O apedrejamento de judeus, tanto em vida como na morte, era prática comum de perseguição e de hostilidade entre os árabes. As sinagogas eram frequentemente apedrejadas pela população quando havia conflitos, revoluções, mudança de sultões, bombardeios, invasões, e outros eventos que enfureciam as multidões, de maioria árabe-muçulmana, que desprezavam e tinham ciúmes daqueles líderes judeus que alcançavam certa posição econômica e social, em alguns governos. Na substituição de algum sultão ou pachá amigo por um inimigo, sempre ocorriam saques e perseguições.

Nas aljamas, juderias e guetos da Ibéria e da Europa era constante a pressão para que os judeus "filhos da maldição, deicidas, párias, e excluídos" fossem catequizados ou convertidos forçosamente. Dessa maneira, cria-se "um novo tipo de meio-judeu e meio-cristão", ou seja, os marranos. No Marrocos, a pressão para

\footnotetext{
${ }^{2}$ LAREDO (1935) apud BENCHIMOL. Eretz Amazônia - os judeus na Amazônia.
} 
que os judeus aceitassem a crença de Maomé e substituíssem a Torá ${ }^{3}$ pelo Alcorão, ${ }^{4}$ para torná-los Judid-al-Islam "muçulmano por fora e judeu por dentro" também se fazia sentir. Muitos casos de conversão forçada ou de martírios ocasionados pela resistência ocorreram.

Uma instituição de fundamental importância e que muito contribuiu para a educação de judeus desse país foi a A.I.U. (Aliança Israelita Universal), fundada em Paris, em 1860. ${ }^{5}$ A Aliança teve como objetivo solidarizar com os judeus, trabalhar pela sua emancipação e progresso moral, oferecer ajuda e assistência às vítimas do antissemitismo, encorajar a publicação de livros que promovessem esses objetivos. Sua ação se fazia nos níveis diplomáticos, na assistência a emigrantes, na educação, visando sobretudo aos judeus orientais vítimas de perseguições. Entre 1870 e 1885 foram fundadas escolas na Bulgária, Sérvia, Romênia, Turquia, Síria, Iraque, Egito, Jerusalém, Argélia, Tunísia e outros países do Mediterrâneo. A Escola Israelita Universal fornecia formação em todos os níveis de ensino: línguas (francês, espanhol, inglês e hebraico), ciências, história, geografia, ofícios e profissões. As mulheres aprendiam costura, trabalhos manuais, música, além das matérias citadas.

Escolas da A.I.U. foram fundadas em Tetuan, em 1862, em Tânger, em 1869, seguidas de mais cinco escolas no Marrocos. As de Tetuan e Tânger desempenharam papel importante na educação e preparação de judeus, tirando-os da pobreza e da ignorância, e estimulando-os a emigrar para outros países com

${ }^{3}$ Torá, ou os cinco livros de Moisés: Gênesis (Bereshit), Êxodo (Shemot), Levítico (Vaikrá), Números (Bamidbar) e Deuteronômio (Devarim).

${ }^{4}$ Alcorão ou Corão é o livro sagrado do Islã. Os muçulmanos acreditam que o Alcorão é a palavra literal de Deus (Alá) revelada ao profeta Muhammad (Maomé) ao longo de um período de 22 anos.

${ }^{5}$ A fundação da A.I.U. se deve à ação de J. Carvalho, I. Cahen, N. Leven, A. Cremieux, A. Astruc e o poeta E. Manuel, apoiada financeiramente pelo Barão Maurício de Hirsch. 
melhores oportunidades. Ajudou, portanto, na preparação dos futuros líderes judeus da Amazônia que se tornaram importadores e exportadores.

A importância dada ao ensino do francês, espanhol, inglês e hebraico nas escolas da Aliança não ajudou na fixação do hakitia no Marrocos, uma vez que este não foi considerado relevante no processo educacional, sendo seu uso restrito aos ambientes familiares e sociais judaicos.

\section{Antecedentes históricos no Brasil: a presença judaica na Amazônia}

Em 28 de janeiro de 1808 foi assinada no Brasil a Carta Régia da Abertura dos Portos às Nações Amigas.

Em 19 de fevereiro de 1810, foram feitos dois tratados, um de comércio e navegação e outro de aliança e amizade, além de uma convenção sobre o serviço de navios entre Brasil e GrãBretanha. O Tratado de Aliança e Amizade determinava que, no futuro, não haveria mais no Brasil o Tribunal da Inquisição. ${ }^{6}$ Falbel $^{7}$ assinala que este tratado constitui um marco e um sinalizador para que os judeus do Marrocos e de outros países pudessem vir para a Amazônia.

Em 18 de junho de 1814, o Príncipe Regente D. João assinou um novo decreto, abrindo os portos luso-brasileiros em caráter definitivo a todas as nações amigas, sem exceção. No ano de 1821, D. João VI, enfrentando as represálias do clero e da Igreja, extinguiu a Santa Inquisição e os Tribunais do Santo Ofício em todo o Reino Unido de Portugal, Brasil e Algarves.

O Imperador D. Pedro I proclamou a Independência do Brasil em 7 de setembro de 1822. A Constituição Imperial de 1824

\footnotetext{
${ }^{6}$ BENTES. Das ruínas de Jerusalém à verdejante Amazônia.

${ }^{7}$ FALBEL. Egon Wolff 1910-1991: coletânea de artigos e conferências.
} 
reconheceu a Igreja Católica como a religião oficial do Estado, permitindo o culto doméstico ou particular de outras religiões em casas "sem forma alguma exterior de templo". As sinagogas poderiam funcionar em casas de famílias judaicas, como ocorreu no início.

Com a Proclamação da República dos Estados Unidos do Brasil, em 15 de novembro de 1889, o governo provisório baixou o Decreto 119 que abole a união legal da Igreja com o Estado, e institui o princípio da plena liberdade de culto. A emigração sefardita marroquina para Belém deu-se por volta de 1810.

O Brasil abriu suas portas para acolher os fugitivos e exilados e se apresentou como um novo lar, uma nova pátria livre das perseguições e temores para aqueles saídos do Marrocos. Os fatores políticos, as leis atraíram migrantes.

Outros fatores atuaram também como atração para a Amazônia: a intensificação da navegação do exterior, propiciando o maior comércio de importação e exportação, cargas e transportes de passageiros e migrantes; a navegação interior subsidiando e propiciando a interiorização das correntes migratórias judaicas ao longo do Rio Amazonas e seus afluentes; o ciclo da borracha, que também atraiu ingleses, franceses, alemães, portugueses e os flagelados e retirantes do nordeste, que fugiam das secas de 1877 e 1888. A combinação dos fatores de expulsão e atração fez com que os judeus saíssem do Marrocos e fossem viver na Amazônia.

\section{As correntes migratórias}

Benchimol $^{8}$ divide a presença judaica na Amazônia, a partir de 1810, em cinco correntes:

1 os sefarditas expulsos de Portugal, Espanha e Marrocos, que falavam português, espanhol e hakitia;

\footnotetext{
${ }^{8}$ BENCHIMOL. Eretz Amazônia - os judeus na Amazônia.
} 
2 os forasteiros nativos do Marrocos, que falavam árabe e berbere; 9

3 os serfatitas ${ }^{10}$ de Alsácia e Lorena, de fala francesa e alemã;

4 os ashkenazitas da Alemanha, Polônia e dos países da Europa Oriental, que falavam alemão e ídiche;

5 os foinquinitas (foinquinos, que em hebraico e hakitia significa "Fenícia") do Oriente Médio, que falavam ladino ${ }^{11}$ e árabe.

Com o advento da exploração da borracha, a emigração judaica para a região amazônica aumentou bastante e os judeus de origem hispano-portuguesa do Marrocos começaram a chegar cada vez em maior número para o Estado do Pará e para o Estado do Amazonas, onde se estabeleceram nas capitais e no interior dos dois estados. Das cinco correntes apresentadas, os grupos mais numerosos e influentes que aportaram na Amazônia foram os judeus sefarditas e forasteiros que emigraram do Marrocos, no período de 1810 a 1910.

\section{Belém do Pará}

Santa Maria de Belém do Grão Pará foi fundada em 1616 por Francisco Caldeira Castelo Branco. A cidade espalha-se pela

\footnotetext{
${ }^{9}$ Berbere era a língua dos povos primitivos que habitavam o interior do Marrocos, a que os sefarditas chamavam de arbia, porque nem mesmo os judeus fluentes em árabe conseguiam entender o seu linguajar nativo.

${ }^{10}$ Serfaty (heb.) - "francês".

${ }^{11}$ Ladino é o termo usado para judeu-espanhol na comunidade judaica em geral. Séphiha (Le ladino (judéo-espagnol calque): structure et évolution d'une langue liturgique) distingue o ladino ou judeu-espanhol calco como a língua escrita religiosa, utilizada pelos judeus da Espanha medieval, na tradução palavra-por-palavra dos textos religiosos, do hebraico para o espanhol. Por ser uma língua de tradução, o autor enfatiza que o ladino não deve ser confundido com o judeu-espanhol oral, em suas variantes oriental e ocidental.
} 
margem da baía do Guajará e do rio Guamá, distante $120 \mathrm{~km}$ do Oceano Atlântico e $160 \mathrm{~km}$ ao sul da linha do Equador.

Belém floresceu com pau-brasil e drogas do sertão e desabrochou com a exploração da borracha. Sua maior riqueza é a floresta bem próxima, com a sua grande biodiversidade que fascina o mundo.

A cidade com $1.065 \mathrm{~km}^{2}$ de território apresentou, no ano de 2005, uma população estimada de 1.405.871 habitantes, conforme os dados do IBGE (<http://www.ibge.gov.br>). Não há dados oficiais sobre a comunidade judaica da cidade, mas através da pesquisa de campo realizada na cidade por Scheinbein ${ }^{12}$ para a dissertação Línguas em extinção: o hakitia em Belém do Pará, constatou-se que a comunidade judaica é constituída aproximadamente de 400 famílias, na sua maioria formada por profissionais liberais. Como ocorre de maneira geral no Brasil, há muitos casamentos mistos, ou seja, de judeus com pessoas de outros credos.

Foram encontrados vários sobrenomes sefarditas em Belém, a saber: Almescany, Assayag, Athias, Azulay, Barcessat, Bemerguy, Bemuyal, Benchimol, Bendayan, Benguigui, Bentes, Benzecry, Gabbay, Israel, Laredo, Levy, Mendes, Nahon, Obadia, Ohana, Pazuello, Serruya, Tobelem, Zagury. Todos esses, por nós verificados, confirmam as relações já publicadas sobre os sobrenomes sefarditas de Belém e na Amazônia. ${ }^{13}$

A língua étnica que um dia os sefarditas marroquinos falaram com fluência, o hakitia, está atualmente, na comunidade em estudo, diluída no português brasileiro, restringindo-se seu uso a situações em que os seus "falantes" se sentem à vontade para, através de expressões, de palavras, de verbos, de provérbios,

\footnotetext{
${ }^{12}$ SCHEINBEIN. Linguas em extinção: o hakitia em Belém do Pará.

${ }^{13}$ Os sobrenomes sefarditas são citados por Bentes (Os sefardim e a hakitía) e Benchimol (Eretz Amazônia: os judeus na Amazônia).
} 
de enunciados carregados de afeto, restabelecer o elo com o passado marroquino distante.

$\mathrm{Na}$ escassa bibliografia sobre essa modalidade do judeuespanhol ressaltam-se duas gramáticas, a saber: a de Benoliel ${ }^{14} \mathrm{e}$ a de Bentes. ${ }^{15}$ Há também o trabalho pioneiro de Guimarães. ${ }^{16} \mathrm{~A}$ maior parte dos estudos sobre o judeu-espanhol centra-se ou no dialeto oriental, especialmente o da Turquia, ou no ladino, a vertente escrita dos textos religiosos sefarditas judeu-espanhóis. A vertente ocidental, o hakitia, é pouco conhecida e ainda pouco explorada.

No que se refere ao léxico, há que se mencionar o dicionário de Benmergui, publicado em 2004, que serviu de termo de comparação para o glossário realizado por Scheinbein, ${ }^{17}$ constituído de palavras ainda existentes na fala dos sefarditas de Belém do Pará e o glossário de Aflalo, de 1999.

O léxico do hakitia é predominantemente espanhol, tem sua origem nos dialetos hispânicos medievais, utilizados pelos judeus ibéricos, acrescidos de formas mais modernas do próprio espanhol, incorporados ao hakitia num processo denominado rehispanização. O vocabulário básico hispânico mesclou-se a outras línguas, como o hebraico, o árabe e, no Brasil, ao português brasileiro.

A seguir serão apresentados provérbios e frases comuns coletados em pesquisa de campo na cidade de Belém. ${ }^{18}$

\footnotetext{
${ }^{14}$ BENOLIEL. Dialecto judeo-bispano-marroquí o bakitía.

${ }^{15}$ BENTES. Os sefardim e a bakitía.

${ }^{16}$ GUIMARÃES. O judeu-espanbol: uma língua neolatina em extinção.

${ }^{17}$ SCHEINBEIN. Línguas em extinção: o hakitia em Belém do Pará.

${ }^{18}$ Dados coletados em pesquisa de campo realizada por Cássia Scheinbein em 2005. Esses fazem parte da dissertação de mestrado Línguas em extinção: $o$ bakitia em Belém do Pará. Dissertação aprovada em 2006, orientada pela Profa. Dra. Maria Antonieta A. M. Cohen na FALE/UFMG.
} 


\section{Provérbios e frases comuns}

1. Achlás, a bueno está: "Basta, está tudo bem."

2. Ai que bien melda tu hicho (tu hichito): "Como é bom quando ele ora, como é bom quando ele recita, que bom que ele estuda teu filho, que bom ele recita teu filho."

3. Aias al Diós cerquita de ti todos los dias: "Encontres Deus perto de ti todos os dias."

4. Aigua mi gueno: "Por que está fazendo isso?"

5. Az bien al malo que te dará con un palo: "Quando fazes bem ao mal ele te dará com um pau (uma maldade)."

6. Asquede ferazmal fulano de tal": "Assim fique fora do mal 'fulano de tal', que não aconteça nada contigo."

7. Baruch atá papá, melech leolan mamá, saquenme desta guachlás que no me aguento mas: "Me tirem desta coisa inoportuna que eu não estou me aguentando mais."

8. Desquito del mal seas: "Desfeito do mal seja."

9. Dió te lo bendiga: "Que Deus te abençõe."

10. Diós bendito aumente mi mazál: "Que Deus aumente mais a minha sorte pela mitzvá que eu cumpri."

11. El alabado su nombre sea anbade en mi salud todo lo bueno que hago: "Acrescente em minha saúde o que eu fiz pelo outro."

12. El Dió me sotrê de todo mal: "Me preserve de todo mal, me guarde de todo mal."

13. El Diós te acuda quando le iames: "O Deus te acuda quando o chame."

14. El mazál de la fea la hermosa la dessea: "A sorte que ela tem de ser bonita isto a feia não tem."

15. El que mucho piensa se acaba sin cenar: "A pessoa que muito pensa acaba sem comer, pensa não faz nada, tem que correr atrás, essa pessoa não pode ficar parada." 
16. El sachen está un perro messor: "A pessoa está como um cão raivoso, não vá atrás."

17. El sachen se quedô con la cara (chala) de açafran: "Ficar com a cara amarelada."

18. El sechut de los sadikin me alcancen: "O merecimento dos justos chegue para mim, me alcancem, algo venha pra mim, algumas cifras cheguem pra mim."

19. El Senbor del olam me cumpla mis desseos huenos: "Que o Senhor do mundo cumpra os meus desejos bons."

20. Entre males hai albares: "Entre males o menor."

21. Falquete de mi: "Desprende de mim (alguém chato)."

22. Ferazmal: "Fique fora do mal."

23. La berachá de Diós no te falte en horas menguadas: "Que a benção de Deus não te falte nas horas difíceis."

24. La berachá del rabino en la esnoga me abre caminos de shalom: "Que a benção do rabino na sinagoga me traga paz."

25. La madre que te pariô

26. La melecina no te falte para tu refuá shelemá: "Que não falte o remédio para a sua saúde completa (pode ser um alento, um conselho)."

27. La mialegri: "Nem me importo."

28. Los dos se mean en el mismo charito: "Os dois são amigos íntimos, os dois sempre estão juntos."

29. Los melachim siempre te acompanhen: "Que os anjos sempre te acompanhem."

30. Mechorado (mejorado) 120 anios e buenos e que io pueda mirar quando lo completes con refuá shelemá: "Almejar que a pessoa chegue aos 120 anos com felicidades, saúde, paz, com tudo de bom e que eu possa ver, assistir, que eu esteja presente neste 120 anos e automaticamente me desejo coisa boa também." 
31. No topes con el sorêr: "Não insistas com o inimigo dos judeus."

32. Non me vai a caparito: "Não vá fazer alguma coisa errada, que possa te fazer algum mal, que possa trazer algum dano."

33. Onde pongas la mano haies provecho: "Encontras proveito, tenhas proveito."

34. Papá, bechame la berachá para que claree mi mazál: "Coloca uma benção para que a minha sorte floresça, coisas lindas tenha, uma sorte boa."

35. Para que este amaiót ?: "Para que este exagero, esta vaidade ?"

36. Para que este guet ?: "Para que este orgulho?"

37. Por dinero (maót) hasta el perro baila: "Por dinheiro até o cachorro dança, faz qualquer coisa, se alegra."

38. Que bien melda tu bicho, vida larga tenga

39. Que Diós reciba nuestras tefilot e las mitzvót con chaim tovim a nosotros e a todos los hichos de Israel

40. Que el uepo saque tus tripas: "Que arranque as tripas da pessoa."

41. Que enduresca tu urina e nunca salga nada: "Que não saia urina porque fica entupido."

42. Que le caiga un mazál: "Que lhe caia uma maldição."

43. Que non salga nunca bassura de tu casa: "Que nunca saia lixo da tua casa."

44. Que te venga unas trechas: "Praga, porrada."

45. Quien cambia de lugar, cambia de mazál: "Quem muda de lugar muda de sorte."

46. Safón de tu padre tu madre uela el dia todo: "Não enche o saco."

47. Se nos olviden las guezerot nunca mas: "Que o mal nos esqueça, que as desgraças nos esqueçam."

48. Se vês las barbas de tu chaber arderlas pon las tuias de achemochar: "Se nem as barbas de teu amigo arderem coloque as tuas de molho." 
49. Tiquito lo chondon: "Te dou um tapa (palmada) na bunda."

50. Trecha de tu madre te cambiô la vida: "Uma surra de sua mãe muda a vida."

Criações de um informante

1. Dias negros vive el gobierno brasilero

2. El Congresso Brasilero está ieno de trampas e chalampas: "O Congresso Brasileiro está cheio de falcatruas e roubalheiras."

3. El mazlin del PT es Eduardo Jeferson: "O delator do PT é Eduardo Jeferson."

4. Endiamantado la sachorá tiene su cuerpo: "A negra tem seu corpo atraente, bonito."

\section{Outras frases em hakitia}

1. Boril negro: "Muito chato."

2. Cierra la puerta: "Feche a porta."

3. Eu te intontei: "Eu te deixei atrapalhado."

4. Isso é pedra e passukim: "Isso é pedra e versículos."

5. Mãe, eu quero macleá: "Mãe, eu quero comer."

6. Mira la sachenita: (usa-se com conotação mais branda): "Olhe a empregada."

7. Não chadreia: "Não fale."

8. Ô manzia negro: "Ô filho da puta."

9. Shofea o chalampão: "Olha o ladrão." 
Resumen: La contextualización socio-histórica del hakitia, lengua románica y judaica, en avanzado proceso de extinción, en la comunidad sefardita de Belém do Pará, Brasil, es presentada en este artículo. Se describe su formación desde el siglo XV, como consecuencia de la diáspora de los judíos de la Hispania Medieval, hasta hoy en Brasil. Especial relevancia es dada a su inserción cultural al largo de ese período de tiempo. Una lista de refranes y frases, con base en datos linguísticos actuales coletados en la dicha ciudad, está presente al final de este artículo.

Palavbas-llave: Contacto linguístico; judeoespañol; sefardita; hakitia; refranes.

\section{Referências}

AFLALO, E. C. Lo que yo sé: manual de haketía. Madrid: Cyan, Proyectos y Producciones Editoriales S.A., 1999.

BEMERGUY, A. Imagens da ilusão: judeus marroquinos em busca de uma terra sem males - Pará, 1870-1910. 1998. Dissertação (Mestrado em História Social) - PUCSP, São Paulo.

BENCHIMOL, S. Eretz Amazônia: os judeus na Amazônia. Manaus: Valer, 1998.

BENMERGUI, I. B. Diccionario de haquetía: guía esencial del dialecto de los judíos del norte de Marruecos. Caracas: Ediciones de la Asociación Israelita de Venezuela y del Centro de Estudios Sefardíes de Caracas, 2004.

BENOLIEL, J. Dialecto judeo-bispano-marroqui o bakitia. Madrid, 1977.

BENTES, A. R. Os sefardim e a hakitia. 2. ed. Belém: Mitograph, 1981.

BENTES, A. R. Das ruínas de Jerusalém à verdejante Amazônia. Rio de Janeiro: Bloch, 1987.

BEREZIN, R.; MEZAN, R. (Org.). Caminhos do povo judeu. São Paulo: Planimpress Gráfica e Editora, 1975. p. 171-228. v. 3. 
COHEN, M. A. A. de M. Línguas não-territorializadas: o haketía, o judeuespanhol oriental e a língua dos "calons". PAPIA, Brasília, Thesaurus Editora, n. 13, p. 82-91, 2003.

FALBEL, N. (Org.). Egon Wolff 1910-1991: coletânea de artigos e conferências. Rio de Janeiro: Instituto Histórico e Geográfico Brasileiro, 1991.

GUIMARÃES, N. S. O judeu-espanbol: uma língua neolatina em extinção. Tese (Doutorado em Estudos Lingüísticos). Universidade Federal de Minas Gerais, Belo Horizonte, 1998.

SCHEINBEIN, C. Uma língua em extinção: o hakitia. PAPIA, Brasília, $\mathrm{n}$. 13, p. 77-81, 2003.

SCHEINBEIN, C. Línguas em extinção: o hakitia. In: ANAIS DO III ENCONTRO NACIONAL DO ARQUIVO HISTÓRICO JUDAICO BRASILEIRO: história, memória e identidade. Belo Horizonte: IHIM: AHJB, 2004.

SCHEINBEIN, C. Línguas em extinção: o hakitia em Belém do Pará. 2006. Dissertação (Mestrado em Estudos Lingüísticos) - Faculdade de Letras, UFMG, Belo Horizonte.

SEPHIHA, H. V. Le ladino (judéo-espagnol calque): structure et évolution d'une langue liturgique. Paris: Association Vidas Largas, 1982. 